\title{
Power Quality Improvement In Lowest/Lift Converter By Fuzzy Logic Practice
}

\author{
K. Boopathy Kannan, Akhil Shine Roy, Kokul. S, Moideen Abdul Mujeeb
}

\begin{abstract}
A fuzzy logic regulator for DC/DC converter is well-defined in this work. The explanation about fuzzy logic and the plan to regulator is given. The fuzzy logic regulator algorithms for controlling the $D C / D C$ converter are pronounced. The suggested regulator practice can adjust the load potential for variable basic potential. Here, numerous present solutions to difficulties, and choosing the greatest tactic contains a transaction between price, efficacy, concerned pulses, THD, harmonic analysis. In the future method, the positive lowest-lift regulator is used and is implemented using three other supervisors. This is distinctive of its kind from the point of cultivating the efficiency, lessening the disturbed pulses content and providing a usual load potential.
\end{abstract}

Keywords: DC-DC Converter, Fuzzy logic regulator, THD.

\section{INTRODUCTION}

In modern years, there have been cumulative demands for tall potential quality and fewer changes in the current drawn from the utility .with the stringent requirement of supremacy quality, low disturbed pulses content has been an active research topic in potential electronics. Lowest-Lift Converter (DC-DC Converter) [1-3] is an exciting subject by regulator point view because of intrinsic nonlinearity. General regulator schemes are potential regulator and current vaccinated regulator. These regulators are requiring a good system knowledge and accurate tuning performance even in wanted small change. This type of regulator is based on variable supply potential, loads that varying with time and presence of parasitic fundamentals to make proper control signals to the difficult plant [4-6]. System mathematical and any complex computations are not required in this approach model [8-9]. PID Regulator and Digital Regulator are applied for lowest/lift converter are compared to fuzzy exchange regulator. These regulator repetitions are human ability to recognize the state of the system and regulator comments. By this regulator strategy is less complex since this is under the utility all comments type: "If the load potential error is positive and its rate of change is negative, and then reduce slightly the duty_cycle," etc. The fuzzy logic regulator was applied to lowest -lift exchange to analyses the change response. [7]. The proposed regulator practice is achieving, the transition problem improvement and reduction in changes fashionable from lowest to lift or lift to lowest when the transition occurs in theatrical and practical experiment result have been verified .

\section{PROPOSED CONTROL SYSTEM}

\section{A. Introduction Fuzzy (Utility Al) Regulator Algorithm}

Fig. 1 shows the general feedback fuzzy regulator design the non fuzzy measurements that have to be fuzzified by fuzzification. The converter not responds to fuzzy regulators directly, the fuzzy regulator rules produced by the fuzzy algorithm. This is defuzzified using defuzzification. Fuzzy regulator includes set of fuzzy regulator comments that are fuzzy implication and the compositional condition of inference. These fuzzy regulator comments are combined by using the sentence connectives and also. For example, the error of the load potential can be defined by utility all unsteady "zero (Z)", "positive low (PS)", "positive average (PM__)". "positive big (PB_ )", "negative low (NS_)", "negative average (NM)", "negative big (NB_)",.

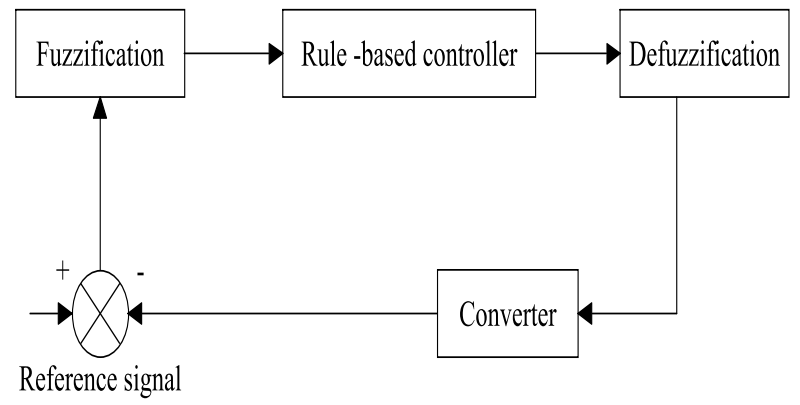

Fig. 1.Feedback Regulator Design

Let $A$ and $B$ be two fuzzy sets in $U$ with association utility $\mu \mathrm{A}$ and $\mu \mathrm{B}$ respectively where $\mathrm{U}$ is the universe of discourse. The universe of discourse is a collection of fuzzy variable possible values $\{\mathrm{x}\}$.

Definition 1: Union

The association utility $\mu(A \cup B)$ of the union $A \cup B$ defined for all $\mathrm{x} \in \mathrm{U}$ by

$$
\mu(\mathrm{A} \cup \mathrm{B})(\mathrm{x})=\max \{\mu \mathrm{A}(\mathrm{X}), \mu \mathrm{B}(\mathrm{X})\}
$$

Definition 2: Intersection

The association utility $\mu(A \cap B)$ of intersection $A \cap B$ is defined for all $\mathrm{x} \in \mathrm{U}$ by

$$
\mu(\mathrm{A} \cap \mathrm{B})(\mathrm{x})=\min (\{\mu \mathrm{A}(\mathrm{x}), \mu \mathrm{B}(\mathrm{x})\}
$$$$
\text { Definition 3: Complement }
$$

The association utility $\mu$ Ãof the complement of fuzzy by,

Revised Manuscript Received on December 30, 2019.

Dr. K.Boopathy*, Professor, Department of Electrical and Electronics Engineering, AVIT, Chennai.Tamil Nadu, India.

Akhile Shine Roy, Kokul.S, Moideen Abdul Mujeeb, UG Students, Electrical Engineering, AVIT, Chennai.Tamil Nadu, India. $\mu \tilde{\mathrm{A}}(\mathrm{x})=1-\mu \tilde{\mathrm{A}}(\mathrm{x})$

Here linguistic variable are used 
N-B: Negative. Big, NM: Negative .Average,

N-S: Negative .Low, Z: Zero, PB_: Positive. Low,

P-M: Positive .Average, PS: Positive. Low

\section{B. BASIC FUZZY LOGIC REGULATOR}

Fuzzy logic regulator is presented by Zadeh in 1965 and is the most fruitful tenders in fuzzy set theory. Utility al unsteady system means that values may be 0 or 1 . A fuzzy set is an addition of a crisp set. Fuzzy sets allow partial association. A fuzzy (utility) set $\mathrm{A}$ is identified by a association utility and to each object grade of association to the set point.

$$
\mu_{\mathrm{A}}: \mathrm{X} \rightarrow[0,1]
$$

From this, fuzzy belongs to universal set defined in a specific problem. A fuzzy set A is called a fuzzy singleton when there is only one element $x_{x}$ with $\mu_{A}\left(x_{x}\right)=1$, while all of the other elements have a association grade equal to zero.

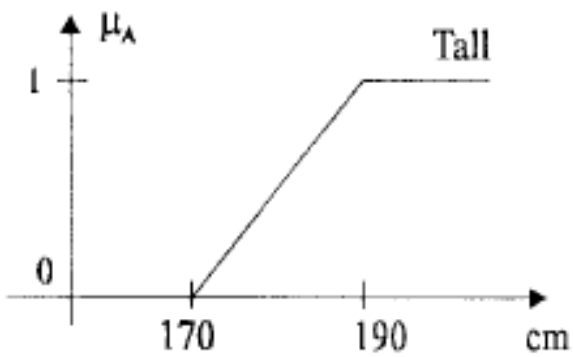

Fig. 2.Association utility related to the fuzzy set labeled Tall

From the figure we know that humans that are above $190 \mathrm{~cm}$ height would be achieve first association grade at the same time below the $170 \mathrm{~cm}$ are received zero grade. But the person that above $180 \mathrm{~cm}$ height would be association of 0.5 .grade. such a method showing the response of the system with the simple and easy relations. i.e. fuzzy sets. The sets are exposed as,

$$
\mathrm{R}_{\mathrm{i}} \text { : if } \mathrm{k} \text { is low THEN } \mathrm{J} \text { is high }
$$

Here $\mathrm{K}$ and $\mathrm{J}$ are fuzzy unsteady, low as well as high are fuzzy sets. For n comments, the condition set is union of rules.

$$
\mathrm{R}=\mathrm{R}_{1} \text { else } \mathrm{R}_{2} \text { else..... } \mathrm{R}_{\mathrm{b}}
$$

A fuzzy logic regulator ler is based on a collection, $\mathrm{R}$, of regulator comments. Interference is consisting the regulator rules. The block diagram of fuzzy regulator scheme comprises four principal components:

- A fuzzy fiction interface -achieve suitable values

- A knowledge base- definitions and regulator condition database

- A decision making logic- that take decisions as a human mind, action according to defined rules.

- A defuzzy fiction interface which yields a non-fuzzy regulator action from an inferred fuzzy regulator action [7]

\section{Block Diagram of Fuzzy Regulator Scheme of DC-DC Converter}

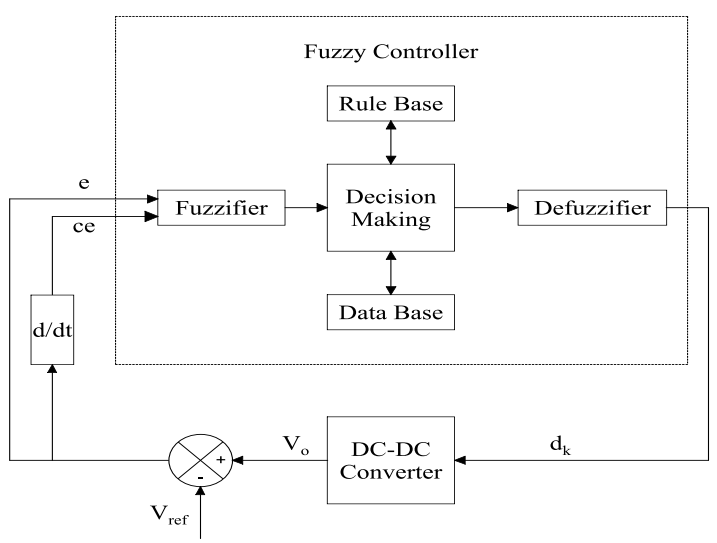

Fig. 3. Block Diagram of Fuzzy Regulator Scheme

The regulator scheme block diagram is exposed in above fig. 3 of converter in fuzzy regulator.

This consists of error and change of error as given below

$\mathrm{e}=\mathrm{V}_{0}-\mathrm{V}_{\text {ref }} ; \quad \mathrm{e}=\mathrm{e}_{\mathrm{k}}-\mathrm{e}_{\mathrm{k}-1}$

Where $\mathrm{V}_{0}$ is the present load potential, $\mathrm{V}_{\text {ref }}$ is the reference load potential, and subscript $\mathrm{k}$ denotes values taken at the beginning of $\mathrm{k}^{\text {th }}$ switching cycle. Fuzzy regulator duty cycle is given by

$$
d_{k}=d_{k-1}+\eta \cdot \alpha d_{k}
$$

$\alpha \mathrm{dk}$ is fuzzy regulator inferred change of duty_ cycle in specimen time of $k, \eta$ is fuzzy regulator gain factor. Tuning $\eta$ attains desired results of plant. The fuzzy unsteady error (e) and change in error (ce) are determined by fuzzy single tons, meaning that these unsteady values are go through the inference process being no fuzzification. Fuzzy comments as $\mathrm{R}_{\mathrm{i}}$ : IF e is $\mathrm{A}_{\mathrm{i}}$ and ce is $\mathrm{B}_{\mathrm{i}}$, THEN $\mathrm{d}_{\mathrm{k}}$ is $\mathrm{C}_{\mathrm{i}}$ [8].

\section{SIMULINK RESULTS (ALL SIMULATION GRAPHS ARE PLOTTED BETWEEN POTENTIAL (V) VS TIME (SEC))}

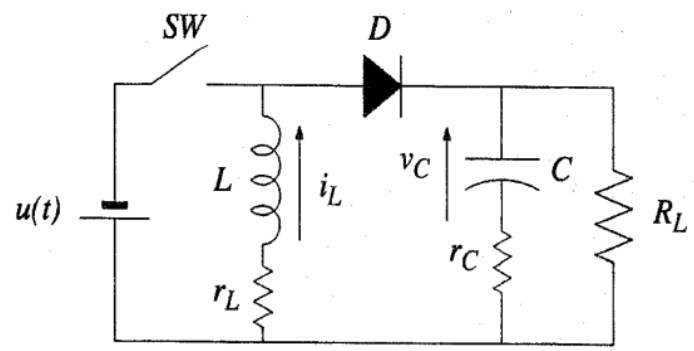

Fig. 4.Circuit Diagram of A Basic Lowest-Lift Converter

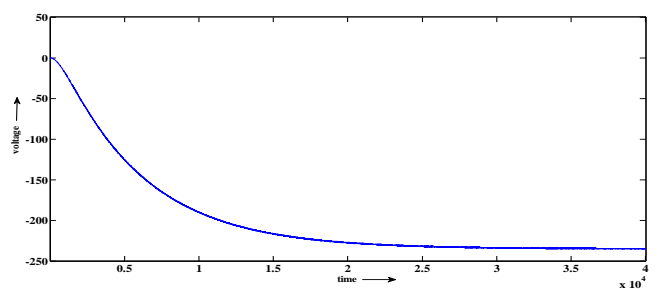

Fig. 5. Load of Lowest lift -converter for triggering

pulse-1 


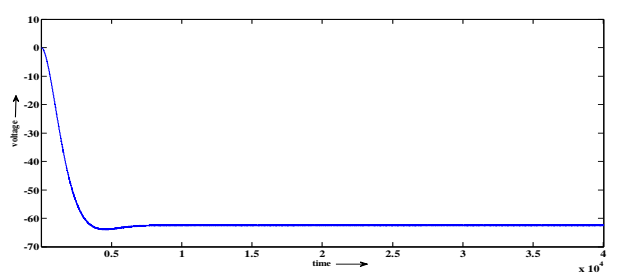

Fig. 6. Load of Lowest Lift -Converter For Triggering

Pulse-2

Fig 4, 5, 6 shows the basic lowest-lift converter circuit. This converter is reducing and boosting perfectly but its load polarity is opposite to that of basic polarity exposed in fig 5 and 6. Lot of methods is there to change its load in positive. By considering cost, number of components required, loss etc. The real time positive lowest-lift converter is better solution to invert the negative load.

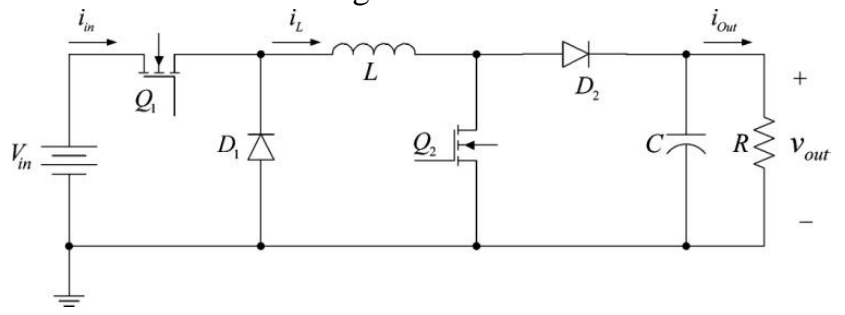

Fig. 7.Circuit Diagram of Positive Lowest-Lift Converter

For a battery-potential request is exposed in Fig. 7. The battery potential is $6.1 \mathrm{~V}$ at the time of complete excitement and the time of settled is $3.6977 \mathrm{~V}$. It is to be constantly supplying a s load of $5.11 \mathrm{~V}$ at steady state. Converter requirements to work at lowest method of retro " $\mathrm{T}_{\mathrm{Ax}}$ " by the lowest-lift method for " $\mathrm{T}_{\mathrm{Bx}}$," as well as final in lift method of " $\mathrm{Tx}_{\mathrm{C}} "$.

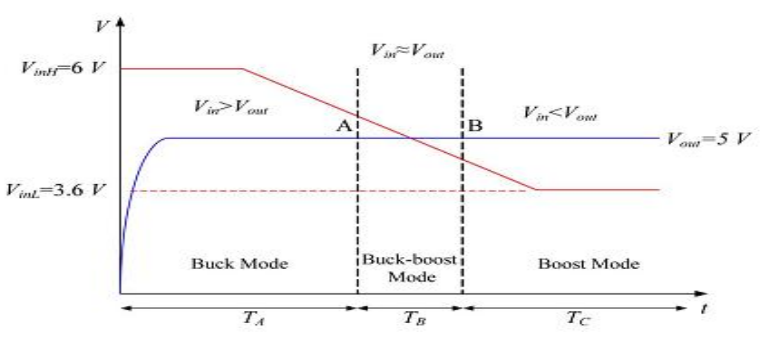

Fig. 8. Basic -Load for the Potential Supply

\begin{tabular}{|c|c|}
\hline Dmin, buck & $6 \mathrm{~V}$ \\
\hline$D_{\max }$, buck $A$, & $\begin{array}{l}\text { Buck } \\
\text { Region }\end{array}$ \\
\hline Buck-Boost Region & $.9 \mathrm{~V}$ \\
\hline$D_{\min }$, boost $B$, & $\begin{array}{r}\text { Boost } \\
\text { Region }\end{array}$ \\
\hline$D_{\max }$, boost & $3.6 \mathrm{~V}$ \\
\hline
\end{tabular}

Fig. 9.Duty ratio dissimilarity for the lowest and lift

method.

The alteration in the duty ratio for different ranges operation that based on various potential is shown in Fig. 8. At the $6 \mathrm{v}$ potential, the duty cycle can be changed from the low value and for the high one, the potential between 4.914 to $5.11 \mathrm{~V}$ roughly as in fig. 2 . The time of "TBx," it can be lowest-lift method. In retro "TCx," obtained in lift method referring to fig. 9 .

\section{DISADVANTAGE OF EXISTING SYSTEM}

In existing systems the majority problematic issue is the load potential spines. It is caused to exchanging and the efficiency is dropped while to lift from low method. In such potential materials the efficiency, size and cost should be measured.

\section{PROPOSED METHOD}

Planned technique is addition of interface exposed, that a mixture of lowest and lift working network. When the foundation potential is above the V1, the converter is working in lowest method. During the time retro, basic potential is stuck between V1 and V2, potential, the mixture A method is in process with the lowest-lift method of both V2 and V3 ranges respectively. In potential V3 and V4 range values, the converter working in the $\mathrm{B}$ mixture method. At last, basic potential is falls below V4; converter purely works in the lift method. In the time of retro "T1" and "T3" just before and after the stage, when the mixture exposed A and B are added, vin $\approx$ v out. The change at the load converter is improved particularly. Procedure of converter in lowest- lift method reducing the converter efficiency. Efficiency, improvement is achieved by only the elimination of lowest-lift method. Time retro T2 is eliminated and operation is done by lowest to lift by using intermediate mixture exposed.

The above system has been analyzed for various supervisors to improve the change response. The supervisors are

- PID Regulator ,Digital regulator

- Fuzzy logic regulator

\section{SIMULATION RESULTS OF SUPERVISOR USED IN POSITIVE LOWEST/LIFTCONVERTER}

\section{A. PID Regulator}

A PID regulator used in industrial control systems widely and it is feedback controller that makes system or plant to steady state through controlled signals based on set point.

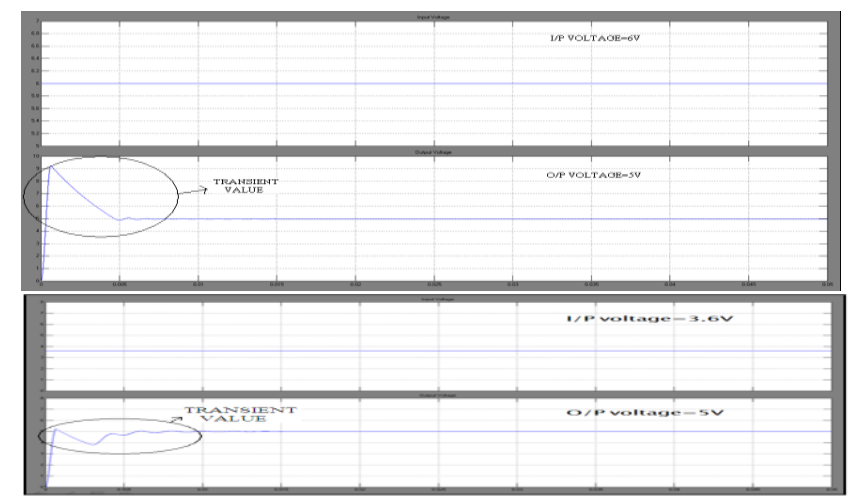

Fig. 10. Basic and load potential s of positive lowest-lift converter

Fig. 10 shows basic and load potential s of positive lowest-lift converter. During lowest method of operation by using PID regulator practice here the expected reference potential is reached at $0.008 \mathrm{sec}$ (table 
II), then it maintains_same load potential throughout the application.

Fig. 11 shows basic and load potential s of positive lowest-lift converter. During lift method of operation by using PID regulator practice here the expected reference potential is reached at $0.0205 \mathrm{sec}$ (table I), then it maintains same load potential throughout the application.

\section{DIGITAL REGULATOR}

A digital regulator (DR) is generally cascaded with a feedback scheme. The organization can either be digital or analog. Requirements of DR are,

- $\mathrm{A} / \mathrm{Dx}$ change analog basic to machine readable format

- $\underline{\mathrm{Dx} / \mathrm{A}}$ change digital loads to a form that can be basic to model

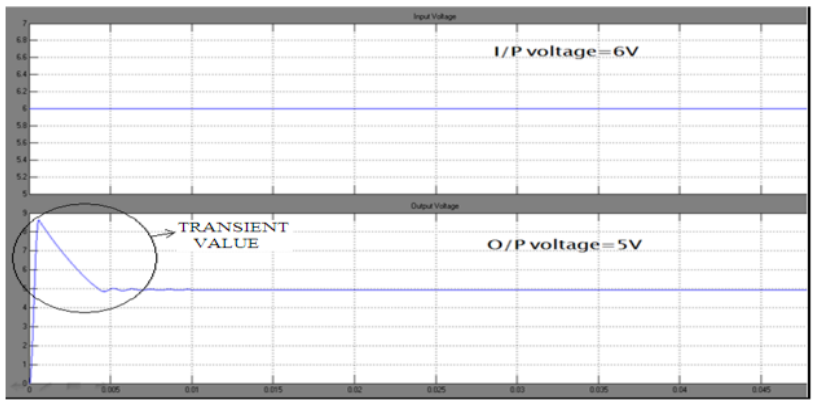

Fig. 11. Basic of Lowest/Lift Converter Using DIGITAL Regulator in LOWEST Method

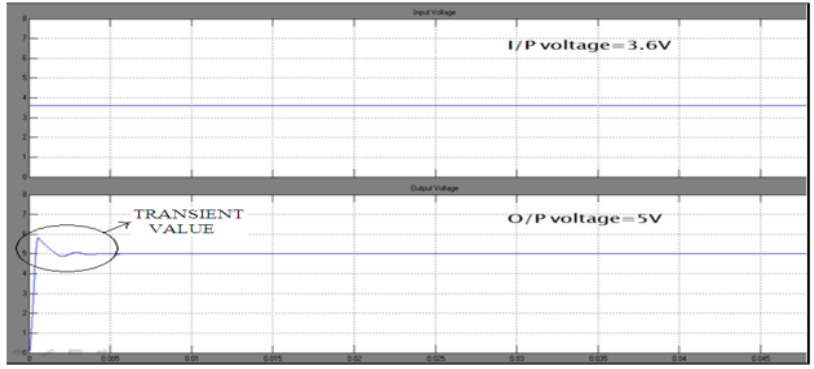

Fig. 12. Basic of Lowest/Lift converter using DIGITAL regulator in LIFT method

Fig. 12 shows basic and load potential of positive lowest-lift converter. During lowest method of operation by using DIGITAL regulator practice here the expected reference potential is reached at $0.006 \mathrm{sec}$ (table II), then it maintains same load potential throughout the application.

Table:I. Comparison of PID, Digital Regulator and Fuzzy Logic Regulator

\begin{tabular}{|c|c|c|c|}
\hline \multicolumn{4}{|c|}{ PID REGULATOR } \\
\hline \multicolumn{3}{|c|}{ LOWEST } & \multicolumn{2}{c|}{ BOOST } \\
\hline Time (s) & Potential $(\boldsymbol{v})$ & Time $(\boldsymbol{s})$ & Potential (v) \\
\hline 0.0005 & 4.7 & 0.0035 & 8.1 \\
\hline 0.001 & 4.5 & 0.0055 & 7.2 \\
\hline 0.0025 & 3.9 & 0.005 & 7.1 \\
\hline 0.004 & 5.2 & 0.007 & 7 \\
\hline 0.005 & 4.8 & 0.0075 & 6.8 \\
\hline 0.0055 & 5.07 & 0.008 & 5.45 \\
\hline 0.006 & 4.9 & 0.015 & 4.88 \\
\hline 0.007 & 5.15 & 0.017 & 5.09 \\
\hline 0.0075 & 4.95 & 0.0205 & 5 \\
\hline 0.008 & 5 & & \\
\hline
\end{tabular}

Table:II. Comparision of PID, Digital Regulator And Fuzzy Logic Regulator DIGITAL REGULATORLER

\begin{tabular}{|c|c|c|c|}
\hline \multicolumn{2}{|c|}{ LOWEST } & \multicolumn{2}{c|}{ BOOST } \\
\hline Time (s) & $\begin{array}{c}\text { Potential } \\
(\boldsymbol{v})\end{array}$ & $\begin{array}{c}\text { Time } \\
(\boldsymbol{s})\end{array}$ & $\begin{array}{c}\text { Potential } \\
(\boldsymbol{v})\end{array}$ \\
\hline 0.0005 & 6 & 0.0005 & 8.2 \\
\hline 0.001 & 5.85 & 0.001 & 7.05 \\
\hline 0.002 & 5.25 & 0.0025 & 6.25 \\
\hline 0.0025 & 4.78 & 0.004 & 5.87 \\
\hline 0.0035 & 5.2 & 0.0065 & 5 \\
\hline 0.004 & 4.9 & & \\
\hline 0.006 & 5 & & \\
\hline
\end{tabular}

Table:III. Comparision of PID, Digital Regulator And Fuzzy Logic Regulator

\begin{tabular}{|c|c|c|c|}
\hline \multicolumn{4}{|c|}{ FUZZY LOGIC REGULATOR } \\
\hline Time (s) & Potential (v) & Time (s) & Potential(v) \\
\hline 0.001 & 8.1 & 0.001 & 6.5 \\
\hline 0.0015 & 7.9 & 0.0015 & 4.89 \\
\hline 0.002 & 7 & 0.002 & 5.1 \\
\hline 0.0025 & 6.5 & 0.0025 & 4.98 \\
\hline 0.003 & 6.1 & 0.003 & 5 \\
\hline 0.0035 & 4.8 & & \\
\hline 0.004 & 4.98 & & \\
\hline 0.0045 & 5 & & \\
\hline
\end{tabular}

Building a Fuzzy (Utility Al) Regulator

A fuzzy set is defined for the basic error variable "e", and the derived change in error, "delta", as well as the "load"

Consider implementing with a micro regulator chip a simple feedback regulator.

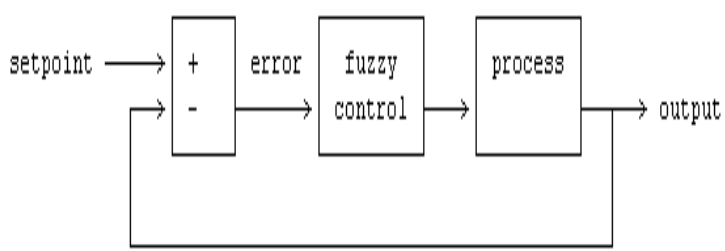

Fig. 13. A simple feedback regulator

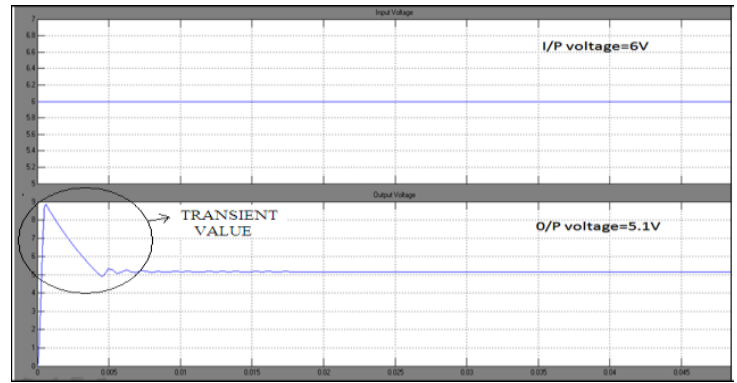

Fig. 14. Basic and Load Potential Waveforms During Lowest Operation

Fig 13 and fig 14 shows basic and load potential s of positive lowest-lift converter. During lift method of operation by using DIGITAL regulator practice here the expected reference potential is reached at $0.0065 \mathrm{sec}$ (table II), then it maintains_same load potential throughout the application.

Therefore digital regulators better than PID regulator since there is a less change time response obtained. 


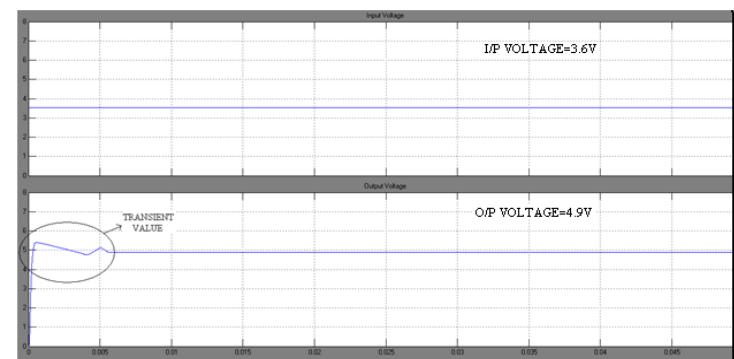

Fig. 15. Basic and load potential waveforms during lift operation

Fig.15 shows basic and load potential s of positive lowest-lift converter. During lift method of operation by using fuzzy logic regulator practice here the expected reference potential is reached at $0.003 \mathrm{sec}$ (table II), then it maintains_ same load potential throughout the application. Therefore here it is observed that fuzzy ( utility al ) regulator is better when compared to PID/DIGITAL supervisor since there is a less change time response obtained.

\section{EXPERIMENTAL RESULT}

A positive hardware lowest-lift converter is implemented according to the constraints tabulated in Table III. The converter utility s in $99 \mathrm{kHz}$ frequency is transferred. For positive lowest-lift argument formation, the MOSS switches with two n-type and schottky diodes are used. IRF540 switches and 1N5817 diodes are used. Texas instrument digital signal processor (DSPx) $(320 \mathrm{~F} 281 \times 2)$ is used by digital Supervisor. Figure 16 show the load potential position is fixed at $5.011 \mathrm{~V}$, as well as basic potential diverges in between 6.019 to $3.619 \mathrm{~V}$.

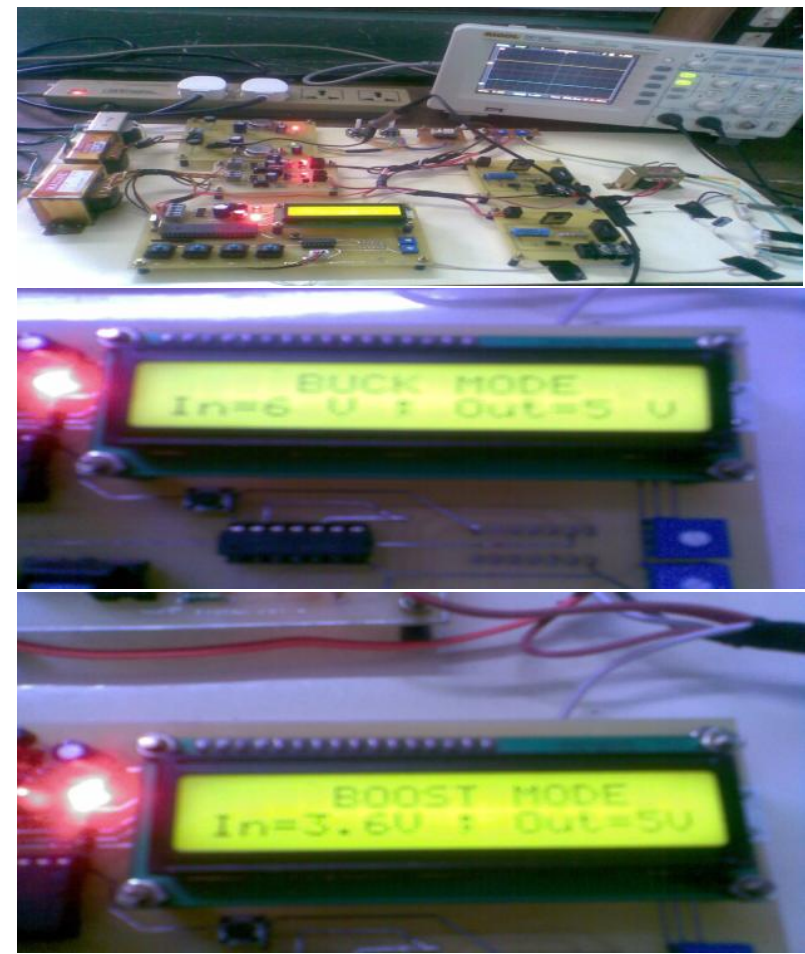

Fig. 16. Shows Basic and Load Potential of Positive Lowest-Lift Converter

\section{CONCLUSION}

Upcoming potential supplies not only require high potential mass, and high efficacy, also integrate intelligent watchdog as obligatory characteristic. Note book processor needs $5 \mathrm{~V}$ potential supply to miscellany of loads as well as some batteries charge up and monitoring the process of battery charging. Initially, fuzzy logic is done "all,". This proposed fuzzy regulator for feedback regulation of Dc_/Dc converter is very modest logic. After that more than one intelligent system are fixed in this regulator and it can perform other intelligent operations that is compact electronic equipment needs. Here, the manager functional to lowest/lift converter are compared in table II. It is observed that constant load reference potential of $5 \mathrm{~V}$ is obtained at quick response of time using fuzzy regulator when compared to other supervisors.

\section{REFERENCES}

1. K. Boopathy, and K. Bhoopathy Bagan, "A Novel Method of Implementing Real-Time Lowest Lift Converter with Improved Change RespoNS_e for Low Potential Applications," in 2011 IEEE ISIEA International Conference organized by IEEE Symposium on Industrial Electronics \& Applications, 2011,pp. 155-160.

2. S. Wakao, R. Ando, H. Minami, F. Shinomiya, A. Suzuki, M. Yahagi, S Hirota, Y. Ohhashi, and A. Ishii, "Performance analysis of the $\mathrm{PV} /$ wind/wave hybrid potential generation system," in Proc. IEEE World Conf. Photovolt. Energy Conv, 2003, pp. 2337-2340.

3. J.H. R. ENS lin and D. B. Snyman, "Combined low-cost, high-efficient inverter, peak potential tracker and regulator for PV applications," IEEE Tran. Potential Electron, vol. 6, no. 1, pp. 73-82, 1991.

4. Boopathy Kannan., Divya Vijay, "Multi-objective Genetic Algorithm based Sliding Method Regulator for Assured Crew Re-Entry Vehicle,' Springer Nature- Journal of Advanced in Intelligent System, vol. 517 no.1, 2017, pp 491-504

5. Boopathy Kannan, Shanthini, "Speed Regulator and Potential factor Correction using Bridgeless Lowest Lift Converter for BLDC Motor Drive," International Journal of Science, Engineering and Technology Research, vol. 4, no. 4, 2015,pp 446- 451.

6. Boopathy, Kannan, and K. Bhoopathy Bagan, "Real-Time Lowest Lift Converter with Improved Change Response for battery Potential Applications," International Journal of Electrical Engineering vol.10,pp. 1-6, 2012.

7. Boopathy, Kannan, and K. Bhoopathy Bagan, "Digital Mixture of Real Time Lowest Lift Converter Using A Soft Practice To Reduce Change Overshoot "International Journal of Electrical Engineering vol.12, pp. 1-6, 2012

8. R. Cardenas, R. Pena, G. Asher, and J. Cilia, "Sensorless regulator of induction machines for wind energy applications," in Proc. IEEE PESC,2002, pp. 265-270.

9. Y.-M. Chen, Y.-C. Liu and S.-H. Lin, "Double-Basic PWM DC_/DC_ converter for high/low potential basics," in Proc. IEEE Int. Telecommun. Energy Conf., 2003, pp. 27-32.

\section{AUTHORS PROFILE}

Dr.K. Boopathy, Professor, Department of EEE AVIT, Chennai.Tamil Nadu, India.
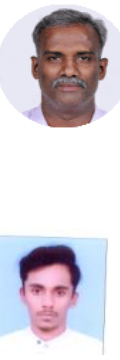

Akhile Shine Roy, UG Student, Department of Electrical Engineering, AVIT-VMRF,OMR Chennai.Tamil Nadu, India.

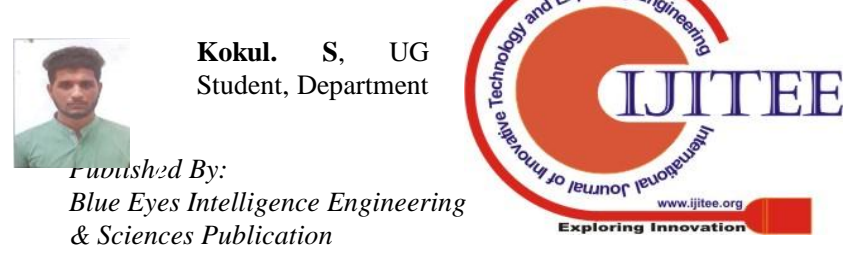


of Electrical Engineering, AVIT, Chennai.Tamil Nadu, India.

Moideen Abdul Mujeeb, UG Student, Department of Electrical Engineering, AVIT, Chennai.Tamil Nadu, India. 